\title{
Clinical and Radiological Features of Cronkhite- Canada Syndrome: A Case Report
}

\author{
Lokesh Lokesh $^{1}$ Vikas Jindal ${ }^{2}$ Prasenjit Das ${ }^{3}$ Rajni Yadav ${ }^{3}$ Govind K. Makharia ${ }^{2}$ \\ Kumble Seetharama Madhusudhan ${ }^{1}$
}

${ }^{1}$ Department of Radiodiagnosis and Interventional Radiology, All India Institute of Medical Sciences, New Delhi, India

${ }^{2}$ Department of Gastroenterology, All India Institute of Medical Sciences, New Delhi

${ }^{3}$ Department of Pathology, All India Institute of Medical Sciences, New Delhi

J Gastrointestinal Abdominal Radiol ISGAR 2022;5:184-190.

\begin{abstract}
Address for correspondence Kumble Seetharama Madhusudhan, MD, FRCR, Department of Radiodiagnosis and Interventional Radiology, All India Institute of Medical Sciences, New Delhi 110029, India (e-mail:drmadhuks@gmail.com).
\end{abstract}

\author{
Abstract \\ Keywords \\ - Cronkhite-Canada \\ syndrome \\ - intestinal polyps \\ - hyperpigmentation \\ - malabsorption \\ - protein-losing \\ enteropathy
}

Cronkhite-Canada syndrome is a rare non-hereditary disease characterized by gastrointestinal hamartomatous polyposis and protein-losing enteropathy. The presenting symptoms are onychodystrophy, skin pigmentation, alopecia, weight loss, and diarrhea. Diagnosis is suggested by a combination of clinical, imaging, and endoscopy findings, and histology is necessary for confirmation. Here we describe a case of a 54year-old man presenting with watery diarrhea, colicky abdominal pain, nasal obstruction, and weight loss for 6 months. Endoscopy showed multiple polyps in the stomach, duodenum, and colon. These were seen on computed tomography (CT) enterography along with polyps in the small bowel. A final diagnosis was made after the biopsy.

\section{Introduction}

Cronkhite-Canada syndrome (CCS) is a rare systemic nonhereditary disease characterized by gastrointestinal (GI) hamartomatous polyposis, ectodermal changes including onychodystrophy, skin pigmentation, and alopecia, weight loss, and diarrhea. ${ }^{1}$ CCS typically manifests in the fifth and sixth decades and is more common in males, with a ratio of $3: 2 .^{2}$ It is associated with high mortality due to complications such as malnutrition, protein-losing enteropathy, gastrointestinal bleeding, and infection. ${ }^{3}$

The pathogenesis of CCS is not fully understood; an autoimmune etiology is proposed. ${ }^{4}$ There is a rare association of CCS with gastrointestinal cancers, including gastric cancer and colorectal cancer. ${ }^{4,5}$ A diagnosis of CCS can be suggested based on the combination of clinical presentation, imaging features, and findings on endoscopy. ${ }^{6}$ Histology is however required in most cases to confirm the disease.

The radiological investigations that assist in the diagnosis include barium studies such as barium upper gastrointestinal study, barium enema, and computed tomography (CT) and/or magnetic resonance (MR) enterography. They also help in the detection of associated pathologies and complications and exclude other diseases with similar clinical presentations. There are sporadic reports discussing the imaging features of $\mathrm{CCS}^{7}$ In this report, we describe the imaging features of a diagnosed case of CCS along with clinical and endoscopic findings. published online February 1, 2022
DOI https://doi.org/ $10.1055 / \mathrm{s}-0042-1742433$. ISSN 2581-9933.

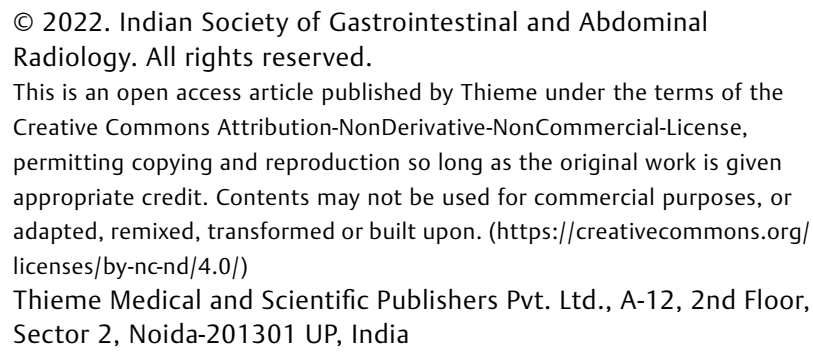



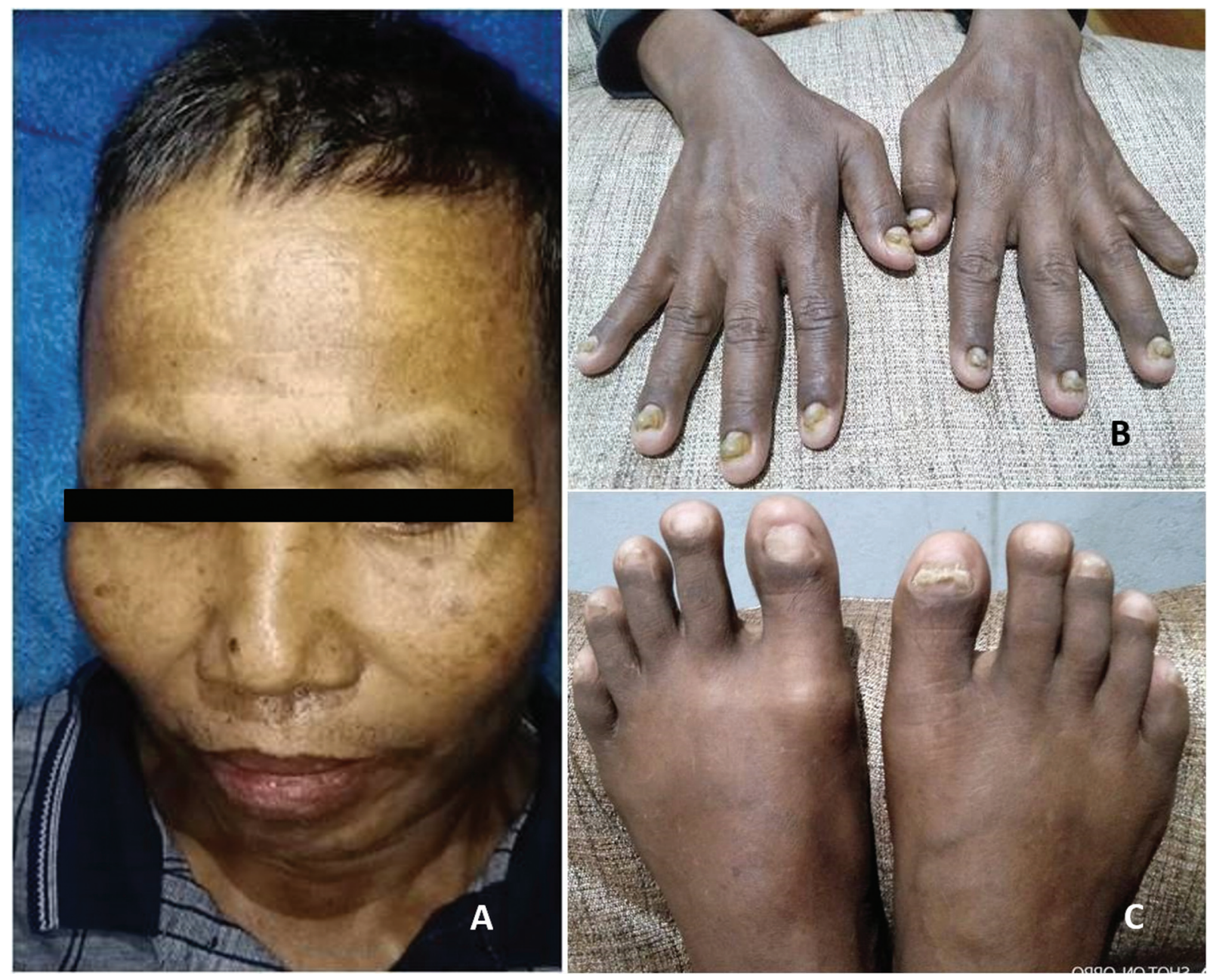

Fig. 1 Physical examination findings of CCS show (A) hyperpigmentation of the skin, dark brown macular lesions on cheeks and forehead, and hair loss on the scalp, eyebrows, and eyelashes. (B) Skin hyperpigmentation on the dorsum of the hand, subungual hyperkeratosis with distal onycholysis, and loss of fingernails. (C) Nail dystrophy, onycholysis, and onychomadesis in the feet.

\section{Case Report}

A 54-year-old male presented to the gastroenterology clinic of our institute with a history of watery diarrhea, colicky abdominal pain, and weight loss of $5 \mathrm{~kg}$ in the past 6 months. The stool frequency was 10 to 15 times/day and was not associated with blood, fat, or oil. Further, there was a history of thickening of nails in all four limbs, scalp hair loss, and darkening of skin for 4 months. There was no history of fever, cough, or shortness of breath. There was a history of endoscopic nasal surgery for nasal polyposis 1 year ago. The family history was unremarkable.

Clinical examination revealed hair loss on the scalp, eyebrows, eyelashes, and limbs with associated onychodystrophy, onycholysis, and onychomadesis (proximal separation of the nail plate from the nail matrix due to a temporary cessation of nail growth). In the present case, most of the finger and toe nail changes started with proximal separation ( - Fig. 1). Laboratory investigations revealed hypoalbuminemia $(2.5 \mathrm{mg} / \mathrm{dL})$, hypoproteinemia $(4.6 \mathrm{~g} / \mathrm{dL})$, mild leukocytosis $\left(16,520\right.$ cells $\left./ \mathrm{mm}^{3}\right)$ with neutrophilia (82.9\%), hemoglobin of $11.7 \mathrm{~g} / \mathrm{dL}$, hematocrit of $35.4 \%$, hypocalcemia ( $7.3 \mathrm{mg} / \mathrm{dL}$ ), and normal serum phos- phate $(3.2 \mathrm{mg} / \mathrm{dL}$ ). The 24 -hour urinary calcium ( $25 \mathrm{mg} /$ day) and phosphate $(775 \mathrm{mg} /$ day $)$ were low. His liver function tests and triple-phase technetium ${ }^{99 m}$ methylene di-phosphonate bone scan were normal. No abnormal radiotracer activity was seen in the blood pool phase and $3 \mathrm{~h}$ and $5 \mathrm{~h}$ delayed phases.

Barium study revealed multiple filling defects in the stomach ( - Fig. 2A), duodenum, and small bowel. Multiple tiny projections (called whiskering due to barium trapped between the small, nodular excrescences of enlarged rugae) were also seen along the greater curvature of the stomach and antrum with thick gastric folds ( - Fig. 2A). CT enterography showed diffuse nodular mucosal thickening of the stomach and duodenum with a large polyp in the first part of the duodenum (-Fig. 2B). Nodular mucosal thickening and multiple small polyps were also seen in the ileum, ileocecal junction ( $\mathbf{F i g} . \mathbf{2 C}$ ), colon, and rectum (-Fig. 2D). All polyps showed homogenous enhancement similar to the mucosa and most of them were sessile in appearance.

Upper gastrointestinal endoscopy revealed diffuse polyposis in the stomach and duodenum ( - Fig. 3) Colonoscopy 


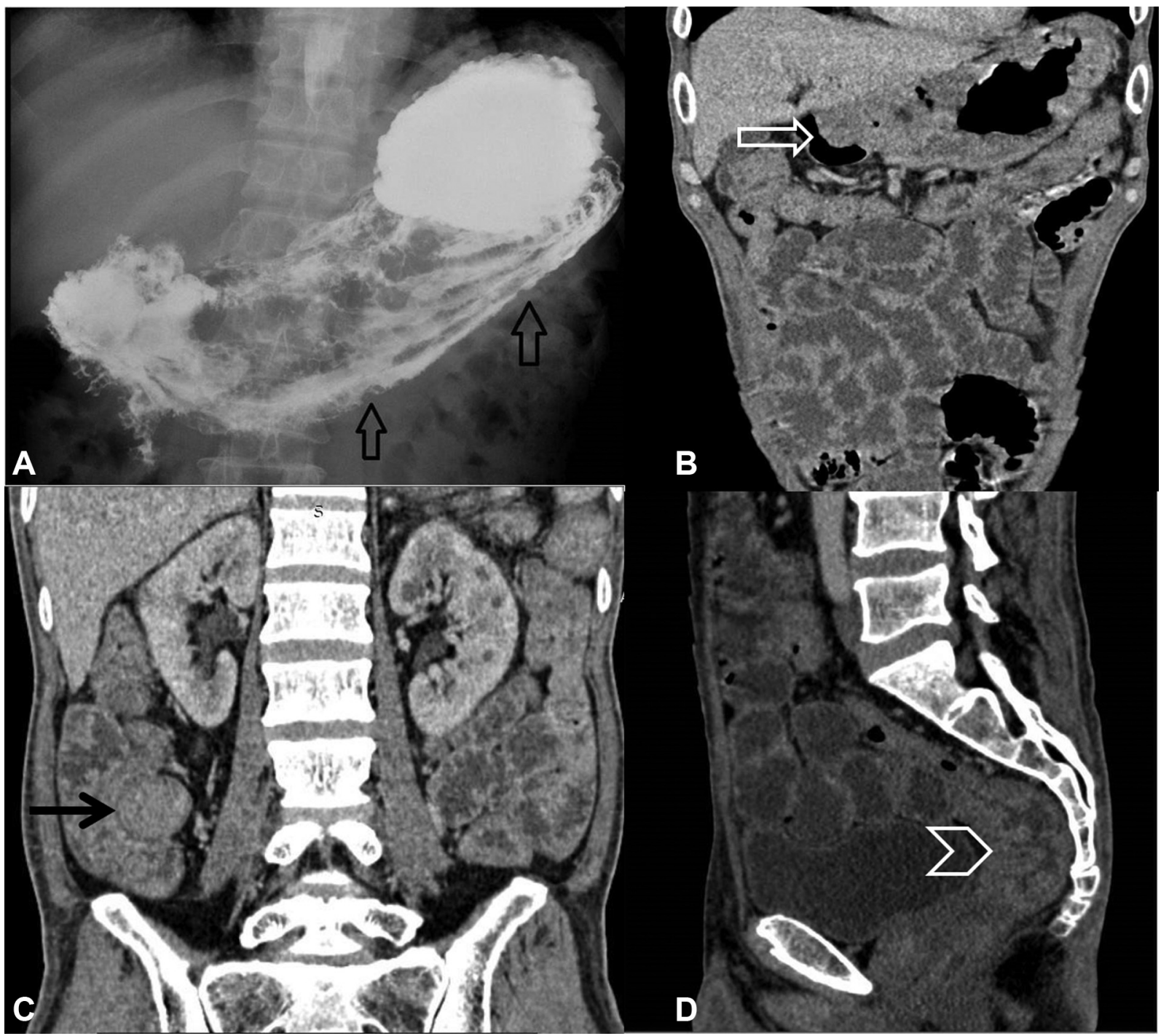

Fig. 2 (A) Barium study shows prominent, thickened, and irregular rugal folds with filling defects and the characteristic whiskering along the greater curvature of the stomach (arrows). (B) Coronal CT enterography image shows the thickened wall of the stomach with a large homogenously enhancing polyp in the first part of the duodenum (arrow). Small bowel loops show mild diffuse thickening of the mucosal folds. (C) Coronal CT enterography image shows large homogenously enhancing polyp at the ileocecal junction (arrow). (D) Sagittal CT enterography image shows mucosal thickening with multiple polyps in the rectum (arrow).

showed edematous mucosa of visualized ileum and cecum with multiple sessile polyps in the ileocecal junction ( - Fig. 3B), colon, and rectum. The frequency of polyps increased from rectum to cecum. Biopsies obtained from the polyps of the stomach, colon, and rectum showed dilated oxyntic glands with markedly irregular foveolar glands and surface villiform changes ( - Fig. 4). The colonic polyps showed cystically dilated irregular crypts with flattened epithelium, luminal mucin pool, and focal micropapillary proliferation of epithelial lining. The polyp stroma was edematous and showed scattered mononuclear cells and eosinophils, suggestive of hamartomatous polyps (-Fig. 4D).

A final diagnosis of Cronkhite Canada Syndrome was established and the treatment was initiated with steroids. After 6 months of follow-up, the patient's symptoms resolved and he is doing well.

\section{Discussion}

Cronkhite Canada syndrome is a rare non-hereditary disease, characterized by gastrointestinal hamartomatous polyposis and protein-losing enteropathy. ${ }^{1}$ More than $75 \%$ of the reported cases are from Japan. The polyps mostly occur in the stomach and colon but can occur anywhere in the GI tract except the esophagus. ${ }^{6}$ Small sessile polyps are more commonly seen than pedunculated ones. ${ }^{8}$ Typically, there is thickening of the gastric rugal folds with polyps carpeting the mucosa. Microscopically, the involved tissue is edematous and inflamed. ${ }^{8,9}$

The etiology of CCS is suspected to be autoimmune in origin and until now no strong evidence of genetic predisposition has been found. Elevated serum levels of IgG4 and ANA (antinuclear antibody) with increased IgG4 mononuclear cell staining are shown to be associated with $\mathrm{CCS}^{10,11}$ An 

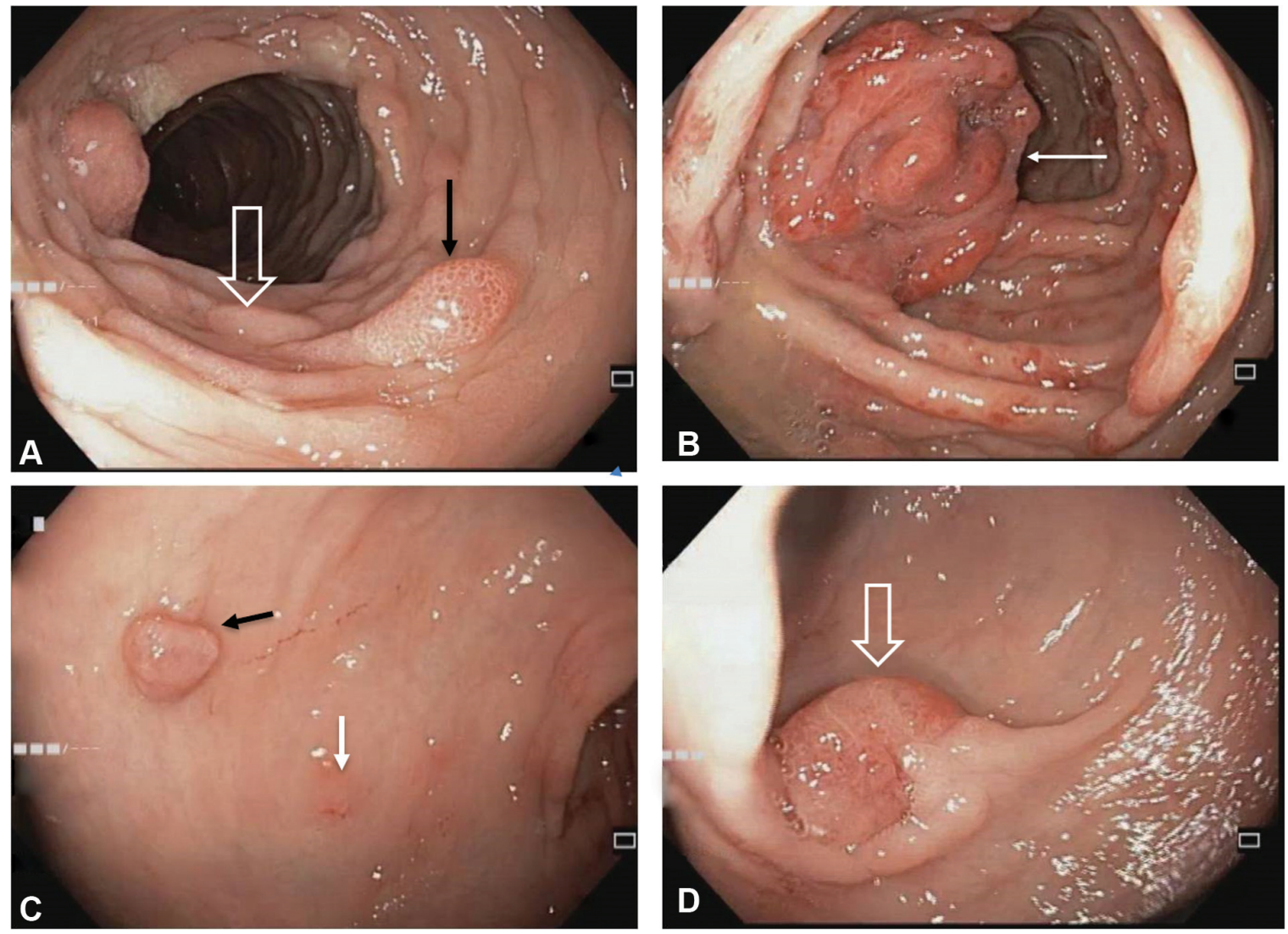

Fig. 3 Endoscopy shows (A) edematous mucosa (open arrow) and sessile polyp (solid arrow) in the ascending colon; (B) a large polyp in the ileocecal junction (arrow); (C) mucosal edema (white arrow) with a polyp (black arrow) in the stomach and; (D) polyp in the first part of the duodenum (open arrow).

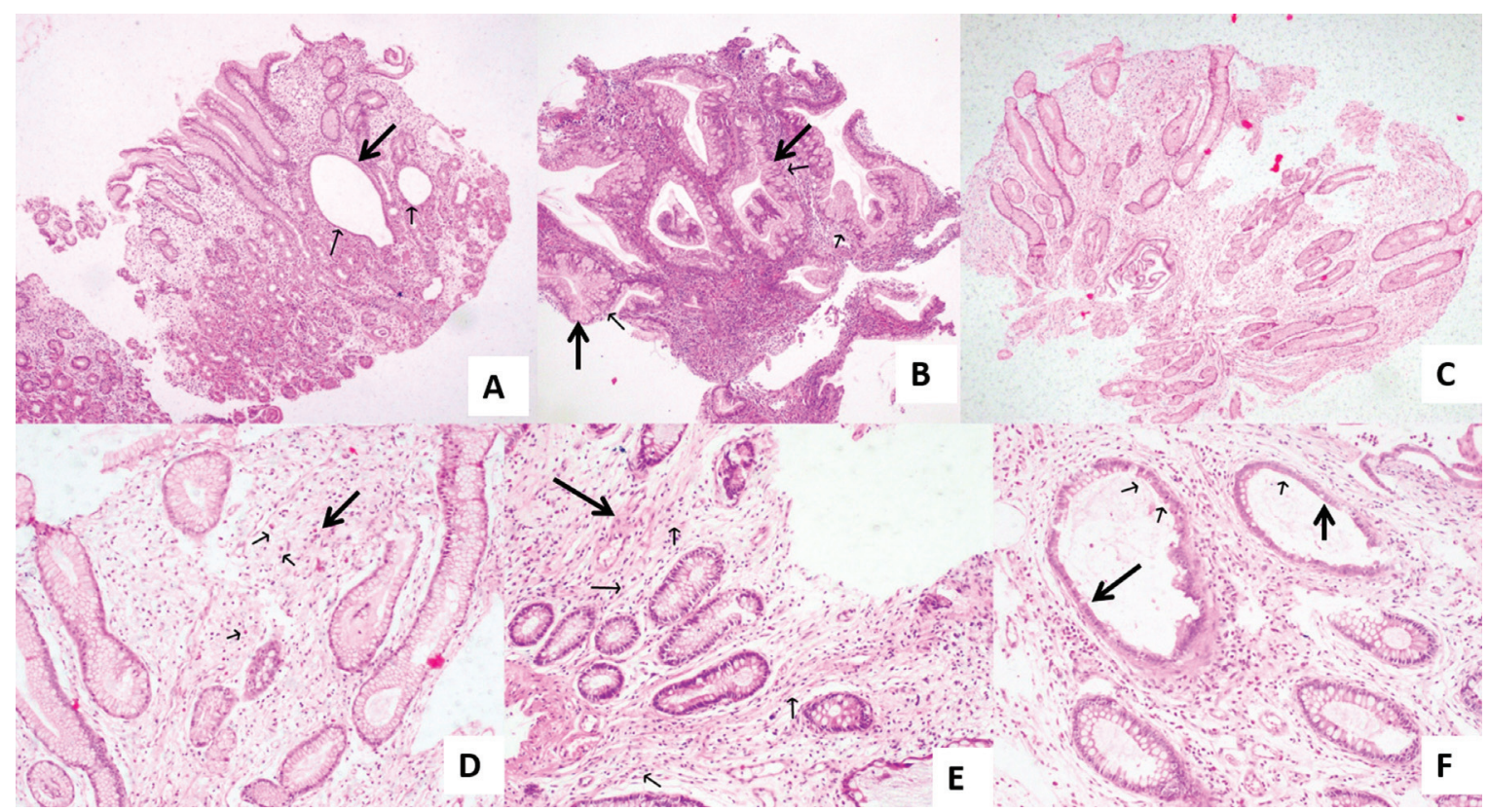

Fig. 4 (A-F) Sections examined from multiple polypectomies show focal features of fundic gland polyp with dilated oxyntic glands (arrows) [A x20], hyperplastic gastric polyp with markedly irregular foveolar glands (arrows) with surface villiform changes [B x40], a sessile gastric polyp with edematous mildly inflamed stroma and irregular branching foveola [C x20]. The polyp stroma is edematous and shows scattered mononuclear cells and eosinophils (arrows) [D x100]. A sessile colonic polyp showing similarly edematous stroma with mononuclear cell infiltrate including eosinophils and splaying of thin collagen and muscle fibers (arrows) [E x 100]. The colonic polyps show cystically dilated irregular crypts with flattened epithelium (arrows), luminal mucin pool, and focal micropapillary proliferation of epithelial lining [F x200]. 


\begin{tabular}{|c|c|c|c|c|c|c|c|}
\hline 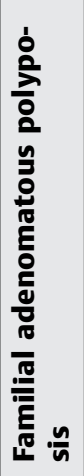 & 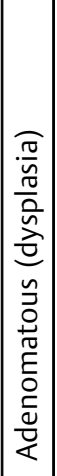 & 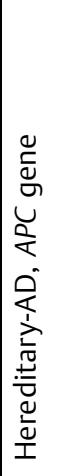 & 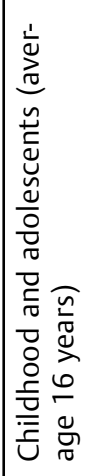 & 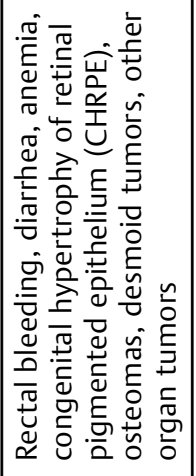 & 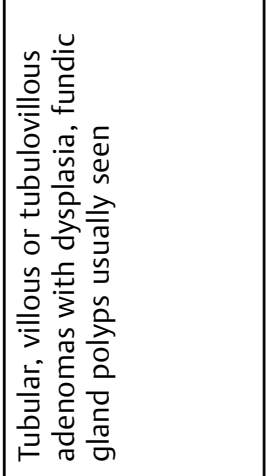 & 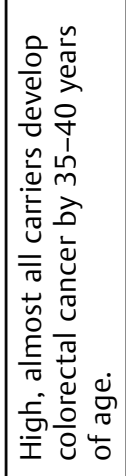 & 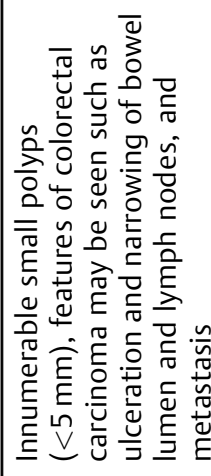 \\
\hline 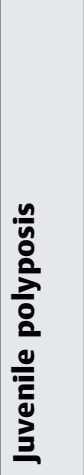 & 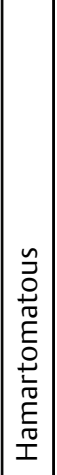 & 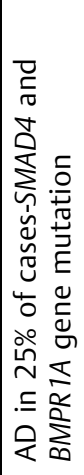 & 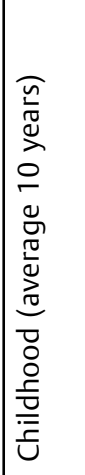 & 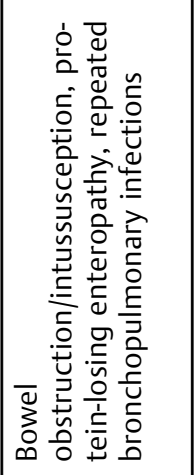 & 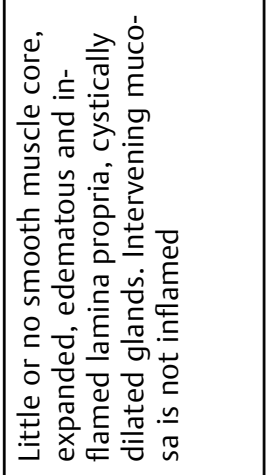 & 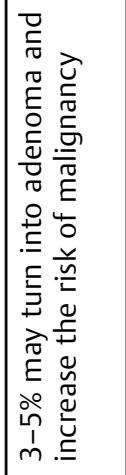 & 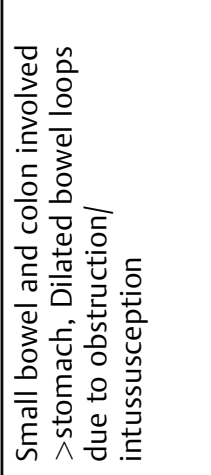 \\
\hline 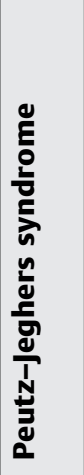 & 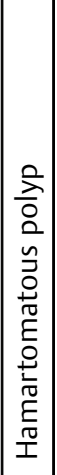 & 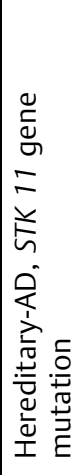 & 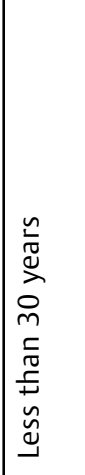 & 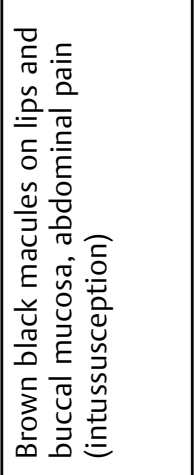 & 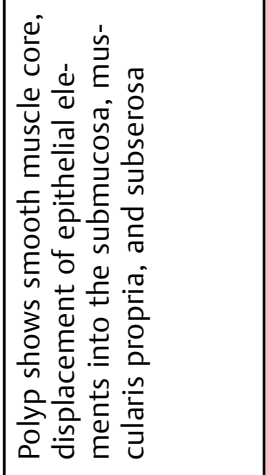 & 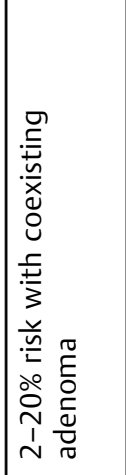 & 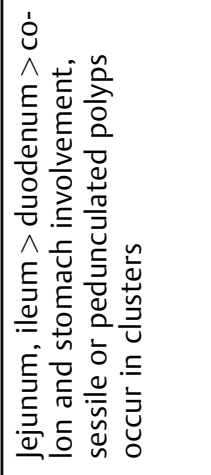 \\
\hline 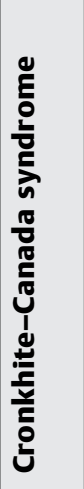 & 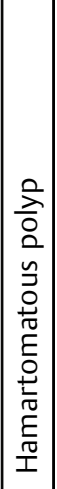 & 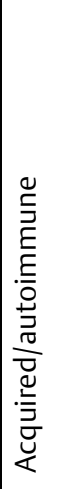 & 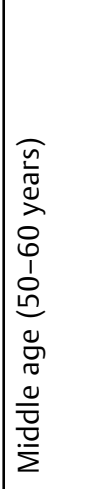 & 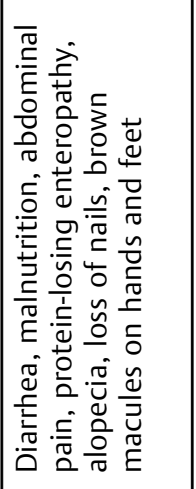 & 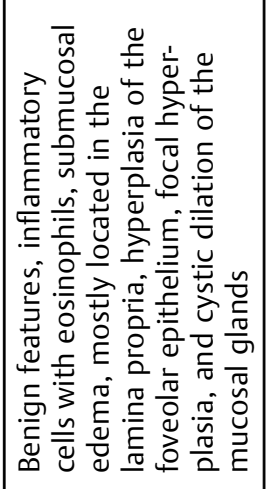 & $\mid$ & 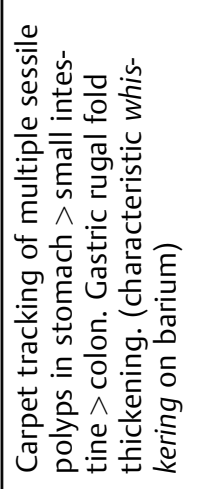 \\
\hline 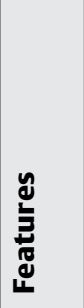 & 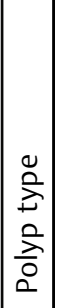 & 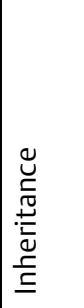 & 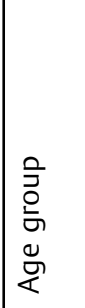 & 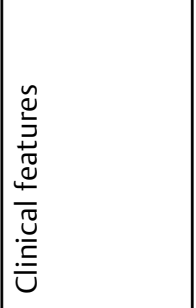 & 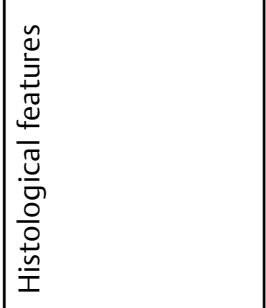 & 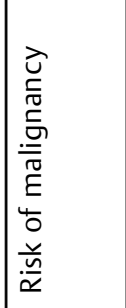 & 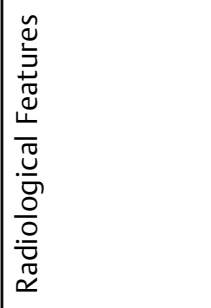 \\
\hline
\end{tabular}


association between CCS and hypothyroidism and other autoimmune diseases including systemic lupus erythematosus, rheumatoid arthritis, and scleroderma has been reported. ${ }^{12}$ Mental and physical stress have also been reported as contributory factors. ${ }^{13}$

The most common initial symptom of CCS is diarrhea along with symptoms related to malabsorption including weight loss, anemia, edema, dysgeusia, and anorexia. ${ }^{9}$ Paraesthesias, seizures, and tetany, because of electrolyte abnormalities, have also been reported. Ectodermal abnormalities associated with the disease include nail dystrophy, thinning, splitting, and shedding from the nailbeds, and alopecia of the scalp and body hair. ${ }^{12}$ The extremities, palms, soles, face, and neck show dark brown macules and hyperpigmentation of the skin. Death in CCS results from GI bleeding, sepsis, and heart failure. The 5-year survival rate is around $55 \%{ }^{14}$

Radiological investigations include CT or MR enterography and barium studies that aid in making a diagnosis and differentiate it from other bowel diseases presenting with similar symptoms. ${ }^{6}$ The radiologist may be the first to suggest a diagnosis in cases where there are mild symptoms or delayed skin changes. In our case, the patient was symptomatic with skin changes which pointed toward a diagnosis of CCS. The radiological appearance of CCS on barium studies includes thickened rugal folds with characteristic "whiskering" (i.e., barium trapped between the interstices of small polyps or barium trapped between the hypertrophied rugae (sulci gastricae) in the stomach, especially along the greater curvature. ${ }^{15}$ Whiskering can also be seen in Menetrier's disease, lymphoma, and other generalized polyposis syndromes such as Peutz-Jeghers syndrome. But this appearance is more commonly seen in CCS due to the innumerable polyps carpeting the stomach. ${ }^{15}$ Polyps in the Peutz-Jeghers syndrome occur in clusters and are more common in thus jejunum and ileum ${ }^{9}$ and thus whiskering is not commonly seen. The polyps are usually small, but thickened folds give the appearance of large polypoidal lesions. The polyps appear as multiple filling defects throughout the GI tract. Barium has now been replaced by CT and MR enterography as the preferred non-invasive investigation for polyposis syndromes due to their higher specificity and sensitivity. CT or MR enterography also demonstrates diffuse polyps throughout the stomach, duodenum, small and large bowel as well as rectum. ${ }^{16}$ Duodenum and ileocecal junction were prominently affected in our case with large polyps. Sessile polyps are usually seen as just thickening of the mucosal folds or bowel wall. Pedunculated polyps are seen as spherical homogeneously enhancing soft tissue masses of variable size, projecting into the lumen of the hollow viscera. Complications such as intussusception with polyp as the lead point may be seen leading to small bowel obstruction.

The differential diagnosis of CCS includes inflammatory bowel disease (IBD) and other polyposis syndromes (-Table 1) such as familial adenomatous polyposis (FAP), juvenile polyposis syndrome, Peutz-Jeghers syndrome, Gardner and Cowden syndrome. ${ }^{17}$ IBD frequently presents with diarrhea and abdominal pain with extraintestinal manifestations, but lacks diffuse polypoidal growth, especially in the stomach. CCS and IBD share similar clinical presentations but differ in the radiological appearances by the presence of polyps in the former and ulceroconstrictive lesions in the latter. Various imaging signs such as comb sign, fat halo sign, mural wall hyperenhancement, and wall thickening help in establishing the diagnosis of IBD. ${ }^{18,19}$ Most of the polyposis syndromes can be differentiated by the age of the patient, family history, distribution of the polyps, and extraintestinal manifestations (- Table $\mathbf{1}$ ). ${ }^{15}$ The gastric rugal thickening of CCS may mimic Menetrier's disease or lymphoma. However, the presence of colonic polyps and the absence of enlarged lymph nodes make CCS more likely in the present case.

Endoscopy shows multiple polyps that coalesce and give a mass-like appearance with thickened edematous mucosa throughout the GI tract. ${ }^{20}$ Biopsy shows features of benign juvenile-like or hamartomatous polyps, mild infiltration of inflammatory cells including eosinophils, massive submucosal edema mostly located in the lamina propria, hyperplasia of the foveolar epithelium, focal hyperplastic features, and cystic dilation of the mucosal glands. ${ }^{17}$ In CCS, the mucosa shows edema, congestion, and inflammation differentiating it from the mucosa in juvenile polyposis where it is normal. ${ }^{6}$

Although no medical therapy is curative, some therapies such as hyperalimentation, corticosteroids, H2-receptor antagonists, antibiotics, cromolyn sodium, anabolic steroids, surgery, and combinations of these therapies have demonstrated improvement in symptoms and a decrease in polyp burden. ${ }^{6}$

In conclusion, Cronkhite-Canada syndrome is a rare multisystem disorder, characterized by gastrointestinal polyposis and malabsorption. The characteristic clinical, radiological, and endoscopic findings help in suggesting a diagnosis. Histology is confirmatory.

Conflict of Interest

None declared.

\section{References}

1 Cronkhite LW Jr, Canada WJ. Generalized gastrointestinal polyposis; an unusual syndrome of polyposis, pigmentation, alopecia and onychotrophia. N Engl J Med 1955;252(24):1011-1015

2 Ward EM, Wolfsen HC. Review article: the non-inherited gastrointestinal polyposis syndromes. Aliment Pharmacol Ther 2002;16 (03):333-342

3 Daniel ES, Ludwig SL, Lewin KJ, Ruprecht RM, Rajacich GM, Schwabe AD. The Cronkhite-Canada Syndrome. An analysis of clinical and pathologic features and therapy in 55 patients. Medicine (Baltimore) 1982;61(05):293-309

4 Safari MT, Shahrokh S, Ebadi S, Sadeghi A. Cronkhite-Canada syndrome; a case report and review of the literature. Gastroenterol Hepatol Bed Bench 2016;9(01):58-63

5 Nonomura A, Ohta G, Ibata T, Shinozaki K, Nishino T. CronkhiteCanada syndrome associated with sigmoid cancer case report and review of 54 cases with the syndrome. Acta Pathol Jpn 1980;30 (05):825-845

6 Sweetser S, Boardman LA. Cronkhite-Canada syndrome: an acquired condition of gastrointestinal polyposis and dermatologic abnormalities. Gastroenterol Hepatol (N Y) 2012;8(03): 201-203

7 Wu Z-Y, Sang L-X, Chang B. Cronkhite-Canada syndrome: from clinical features to treatment. Gastroenterol Rep (Oxf) 2020;8 (05):333-342 
8 Koehler PR, Kyaw MM, Fenlon JW. Diffuse gastrointestinal polyposis with ectodermal changes. Cronkhite-Canada syndrome. Radiology 1972;103(03):589-594

9 Harned RK, Buck JL, Sobin LH. The hamartomatous polyposis syndromes: clinical and radiologic features. AJR Am J Roentgenol 1995;164(03):565-571

10 Fan R-Y, Wang X-W, Xue L-J, An R, Sheng J-Q. Cronkhite-Canada syndrome polyps infiltrated with IgG4-positive plasma cells. World J Clin Cases 2016;4(08):248-252

11 Takeuchi Y, Yoshikawa M, Tsukamoto N, et al. Cronkhite-Canada syndrome with colon cancer, portal thrombosis, high titer of antinuclear antibodies, and membranous glomerulonephritis. J Gastroenterol 2003;38(08):791-795

12 Kao KT, Patel JK, Pampati V. Cronkhite-Canada syndrome: a case report and review of literature [Internet]. Vol. 2009, Gastroenterology Research and Practice. Hindawi; 2009:e619378. Available from: https://www.hindawi.com/journals/grp/2009/619378/

13 Goto A. Cronkhite-Canada syndrome: epidemiological study of 110 cases reported in Japan. Nihon Geka Hokan 1995;64(01): 3-14

14 Anderson RD, Patel R, Hamilton JK, Boland CR. Cronkhite-Canada syndrome presenting as eosinophilic gastroenteritis. Proc Bayl Univ Med Cent 2006;19(03):209-212
15 Kilcheski T, Kressel HY, Laufer I, Rogers D. The radiographic appearance of the stomach in Cronkhite-Canada syndrome. Radiology [Internet]. 1981 Oct 1 [cited 2020 Aug 8]; Available from: https:// pubs.rsna.org/doi/abs/10.1148/radiology.141.1.7291542

16 Dachman AH, Buck JL, Burke AP, Sobin LH. Cronkhite-Canada syndrome: radiologic features. Gastrointest Radiol 1989;14(04): 285-290

17 Kopáčová M, Urban O, Cyrany J, et al. Cronkhite-Canada Syndrome: Review of the literature. Gastroenterol Res Pract [Internet]. 2013 [cited 2020 Sep 18] 2013. Available from: https://www. ncbi.nlm.nih.gov/pmc/articles/PMC3863521/

18 Ahualli J. The fat halo sign. Radiology 2007;242(03):945-946

19 Panizza PSB, Viana PCC, Horvat N, et al. Inflammatory bowel disease: current role of imaging in diagnosis and detection of complications: gastrointestinal imaging. Radiographics 2017;37 (02):701-702

20 Samet JD, Horton KM, Fishman EK, Iacobuzio-Donahue CA. Cronkhite-Canada Syndrome: Gastric Involvement Diagnosed by MDCT [Internet]. Vol. 2009, Case Reports in Medicine. Hindawi; 2009 [cited 2021 Feb 7]. p. e148795. Available from: https:// www.hindawi.com/journals/crim/2009/148795/

21 Shussman N, Wexner SD. Colorectal polyps and polyposis syndromes. Gastroenterol Rep (Oxf) 2014;2(01):1-15 